\title{
Comparative Analysis of Tube Piercing Processes in the Two-Roll and Three-Roll Mills
}

\author{
Zbigniew Pater ${ }^{1 *}$, Wójcik Łukasz' ${ }^{1}$, Patrycja Walczuk ${ }^{1}$ \\ 1 Lublin University of Technology, Mechanical Engineering Faculty, Nadbystrzycka 36., 20-618 Lublin, Poland \\ * Corresponding author's e-mail: z.pater@pollub.pl
}

\begin{abstract}
The article presents a comparison of the piercing process conducted in a two-roll Diescher mill and a three-roll mill. The comparative analysis was based on the numerical simulations of the aforementioned processes, obtained using Forge NxT 1.1. software. It was stated that the most favourable manufacturing method is skew rolling in three-mill rolling mills. The mills operating in this scheme are less energy-consuming, whereas the manufacturing time is $30 \%$ shorter.
\end{abstract}

Keywords: tube piercing, strain, damage, FEM.

\section{INTRODUCTION}

Piercing of thick-walled tubes is one of the basic processes in production of seamless tubes. It can be conducted by skew rolling, extruding in a press or piercing in a press piercing mill. As far as rolling is concerned, two basic groups of machines can be mentioned, mainly two-roll skew rolling mills, additionally equipped with two guiding devices (roll, flat or disc guide) or threeroll rolling mills without guiding devices.

Since the tube piercing processes conducted in skew rolling mills are extremely complicated, FEM-based numerical modelling is used in their analysis. The first study on this subject was published in the 1990s by Urbański and Kazanecki [1], who assumed that the process occurs in axially-symmetric state of strain. A software they developed allowed for monitoring the changes to strain in longitudinal section of the thick-walled tube. The proposed solution was later used for analysing the process of tube elongating in Diescher mill by Malinowski et al [2].

Mori et al. [3] introduced an analysis that considered the spatial shape of the rolled object. In the adopted solution a homogenous elongation of the material in the forming zone was assumed. The forming zone was divided into separate cross sections, analysed using FEM and assuming the plane state of strain. In the calculations friction on the material-piercing plug contact surface was omitted. The described model of the rolling process was further developed by Yoshimura et al. [4], who partially included the influence of friction on the piercing plug. It was assumed that in the circumferential direction friction is described by Coulomb model (when $\mu=0.25$ ), whereas in the direction of elongation friction coefficient is equal 0 . With such assumptions made, an analysis of the influence of rotational speed of the plug on non-dilatational strain in the circumferential direction was conducted.

Subsequent works, also in 2D conditions, focused on determining the crack moment of the material. Ceretti et al. [5] applied the maximum tensile stress criterion, assuming that the material (AISI1020 grade steel) cracks when stress reaches the value of $30 \mathrm{MPa}$. The aforementioned analysis does not include the piercing plug. A similar simulation was performed by Capoferri et al. [6] using a commercial Deform software. As a result of this it was stated that material cracking during the piercing process in influenced by the following factors: temperature, friction, shape of the rolls, material of the rod and plug positioning. 
First attempts at conducting the piercing process in 3D [7] were limited to the initial forming stage, where the material does not come in contact with the plug. An example of such a situation is a study by Pietsch and Thieven [8] in which the distribution of stress and strain in the longitudinal section of the pierced tube was obtained. In the calculations, however, the thermal aspects/ issues were completely omitted. A similar solution was implemented by Ceretti et al. [9], who used simplified rolls, limited to the shaping cone (the output cone was omitted). The analysis focused on the influence of the plug positioning on the rolling process. It was stated that excessive advance of the plug causes its fast wear. In the case of insufficient advance of the plug, superfluous oxidization of the inner surface of the tube may occur, which would influence the quality of the final product. In order to reduce the calculation time Komori [10] proposed using a billet with a plug-shaped indentation in the front. This solution allowed for obtaining the diameter dimensions of the tube, as well as force parameters of the rolling process. A similar solution was applied by Berazategui et al. [11], who compared the results of the calculations with the conducted experiment. The comparison showed compliance as far as the shape of the cross section of the rolled tube is concerned.

A full simulation of the piercing process in the Diescher mill, including the initial and established phases, was conducted by Pater et al. [12]. The calculations, performed in MSC SuperForm software, were the first to include heat phenomena that occur in the product. The aforementioned model was developed by Pater and Kazanecki [13] and further on used in the analysis of load of the piercing plug, modelled as an elastic object. As a result of the calculations changes in temperature of the piercing plug during the rolling process as well as distribution of surface pressure were observed. The highest values of surface pressure $(100 \div 180 \mathrm{MPa})$ were detected in the nose of the piercing plug.

Later on, the model of the piercing process conducted in Diescher mill, researched by Pater et al. was used to determine the influence of the basic parameters of the process on the process itself. Results of the research were published in specialist literature $[14,15]$. Similar calculations were made by Zhao and Mao [16], who researched the influence of the feed angle of the rolls (in the range $8^{\circ} \div 16^{\circ}$ ) on the piercing process. As a result of the analysis it was stated that increasing the value of this angle increases effectiveness of the rolling process, but simultaneously significantly decreases the quality of the product. In another work Zhao et al. [17] presented the results of a simulation of the piercing process with a very significant feed angle $\left(\Theta=24^{\circ}\right)$ and analysed the influence of the plug placement on force parameters of forming and the quality of the finished product. As far as Murillo-Marrodan et al. [18] are concerned, they conducted an analysis to determine which friction model is the most suitable for simulations of the piercing process. Using the Forge software they examined three friction models, mainly Coulomb, Tresca and viscoplastic friction model. Based on the conducted analysis it was stated that Tresca and viscoplastic models provide conditions that are most similar to reality, assuming that the value of friction coefficient is in the range of $0.7 \div 0.8$.

The above presented examples of the 3D numerical modelling of the piercing process did not include the models of material cracking. For the first time such model (compliant with CockroftLatham criterion) was applied in 2008 by Chastel et al. [19]. The simulation, however, was limited to the initial forming phase and did not take into account the piercing plug. Ghiotti et al. [20] have modelled the piercing process to a similar extent. Their simulations included a new material cracking criterion, considering the defects occurring in the axial area of the ingot. Another approach towards weakening of material in the axial area of the ingot was introduced by Joun et al. [21], who used billet with axial holes with the diameter from 2 to $10 \mathrm{~mm}$, instead of modelling the effect of material weakening. As a result of the calculations it was stated that the Mannessmann effect was observed only in the case of billets with small diameter. As far as the billet with the smallest diameter is concerned, the hole was enlarged twofold. It was therefore proven that in the simulation of the piercing process the weakening of the material in the axial area should be taken into consideration.

An interesting approach towards the modelling of the piercing process was presented by Skripalenko et al [22], who initially simulated (using ProCAST software) ingot casting and afterward the results (including, among others, the porosity of the material) were transferred to QForm software, where the piercing process was simulated. As a result of the calculations the influence of the 


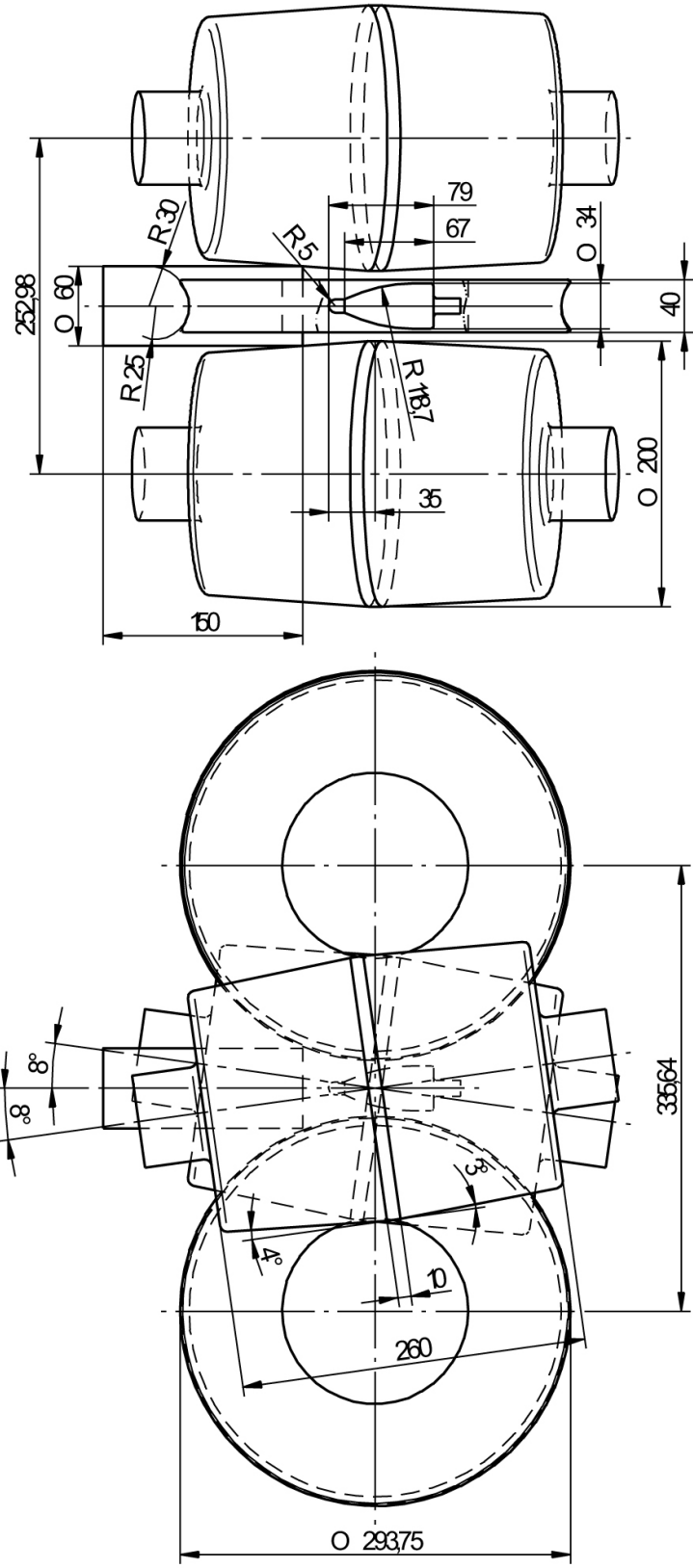

Fig. 1. Scheme of the piercing process in two-roll Diescher mill shape of the piercing plug on the piercing process was determined. QForm software was also used by Romantsev et al. [23] to simulate an innovative piercing process using four rolls (two rolls with the diameter equal $150 \mathrm{~mm}$ and remaining two $110 \mathrm{~mm}$, with the billet diameter $60 \mathrm{~mm}$ ). It was also stated that adopting the new method allows for obtaining a tube of a better quality, while reducing the energy consumption.

Upon the examination of the results of the numerical analyses it is to be stated that no full model of the piercing process in a two-roll rolling mill that would include material weakening in the axial area of the billet has been presented. Furthermore, no works on modelling the piercing process in three-roll rolling mill are to be found. The singular works on this subject present modelling the skew rolling process of rods. For example Stefanik et al. [24] analysed the case of rolling A1050 aluminium rods with $20 \mathrm{~mm}$ diameter, using Forge software. The authors stated that during the rolling process temperature rose significantly (from $390^{\circ} \mathrm{C}$ to $460^{\circ} \mathrm{C}$ ).

In order to fill the gap in the analyses of piercing processes in three-roll mills an analysis of this forming process was conducted. Its results are presented in this article. In order to simplify the interpretation of the obtained results, they were compared to the process of piercing in a two-roll Diescher mill, which was numerically analysed as well as experimentally verified multiple times.

\section{MODELS OF THE PIERCING PROCESS}

In order to compare the piercing processes conducted in two-roll Diescher mill and a threeroll mill, models of those processes were ob-
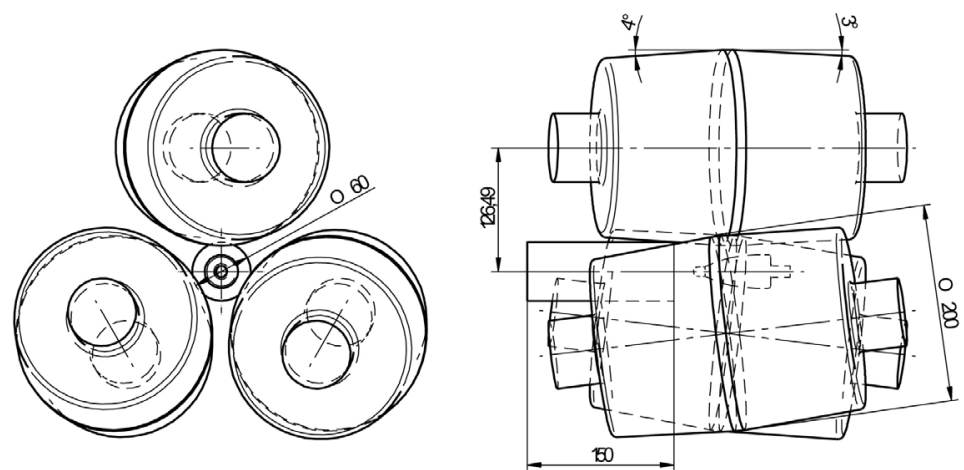

Fig. 2. Scheme of the three-roll piercing process (piercing plug and its placement is similar to the one from the two-roll piercing process, shown in Fig.1) 

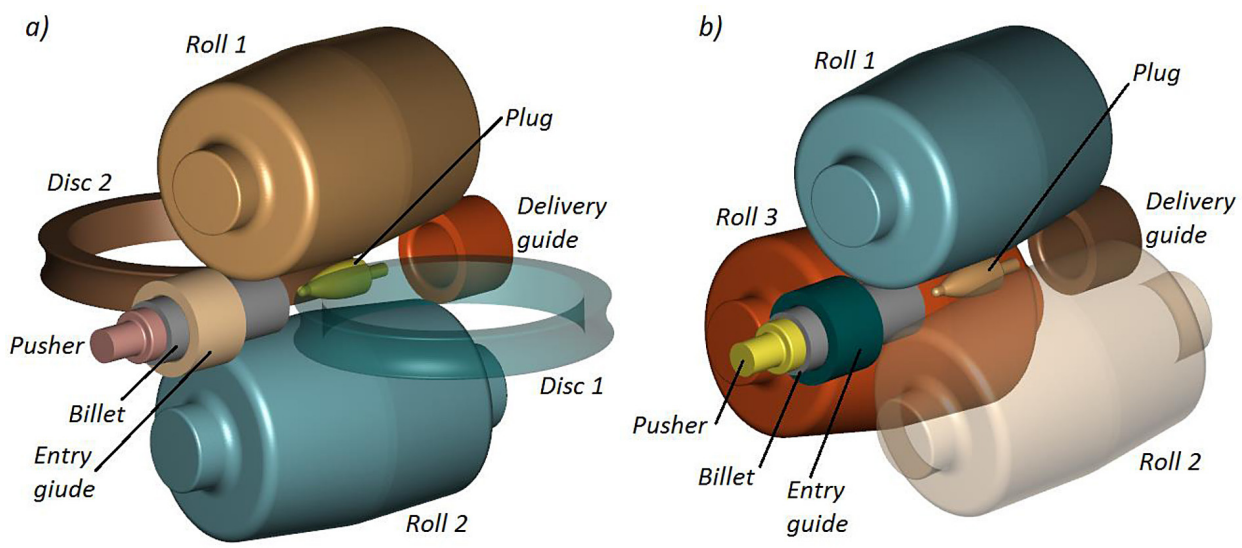

Fig. 3. The geometrical models used in the numerical analysis of the piercing process with: a) two rolls, b) three rolls

tained and are schematically presented in Figure 1 and 2 . In both models similar rolls, piercing plug and billet were used. The placement of the piercing plug and the feed angle of the rolls $(\Theta=$ $8^{\circ}$ ) were also analogous.

Based on the schemes geometrical models of the piercing process were developed, using the commercial software Forge NxT 1.1. The aforementioned models are presented in Figure 3. In those models, apart from the tools presented in Figure 1 and 2, a pusher and entry and delivery guides were used.

In the simulations it was assumed that the billet was made of $100 \mathrm{Cr} 6$ grade steel, which material model is described by the equation:

$$
\sigma_{f}=2707.11 e^{-0.00325 T} \varepsilon^{-0.13502} e^{0.05494 / \varepsilon} \dot{\varepsilon}^{0.1529}
$$

where: $\sigma_{f}$ - flow stress, MPa; $\varepsilon$ - effective strain, -; $\dot{\varepsilon}$ - strain rate, $\mathrm{s}^{-1} ; \mathrm{T}$ - temperature, ${ }^{\circ} \mathrm{C}$.

It was also assumed that the billet was heated to $1180{ }^{\circ} \mathrm{C}$ before rolling, whereas the temperature of the tools was constant and equal: $600{ }^{\circ} \mathrm{C}$ for the piercing plug, $150{ }^{\circ} \mathrm{C}$ for the rolls, $50{ }^{\circ} \mathrm{C}$ for the guiding devices in the Diescher mill and $200{ }^{\circ} \mathrm{C}$ for the remaining tools.

As far as the friction conditions are concerned it was assumed that they are compliant with Tresca law of friction. It was, however, noted that the friction coefficient is equal: 0.95 for the rolls, 0.8 for guiding devices, 0.1 for the piercing plug and 0 for the remaining tools, where the occurrence of sliding friction was assumed. As far as the kinematics of the process is concerned it was assumed that in both cases the rolls are moving at the same speed, equal 60 $\mathrm{rpm}$, whereas the guiding devices are moving at the rate of $6.8 \mathrm{rpm}$.

\section{OBTAINED RESULTS}

Numerical simulations of the process of piercing tubes was conducted in Forge NxT 1.1
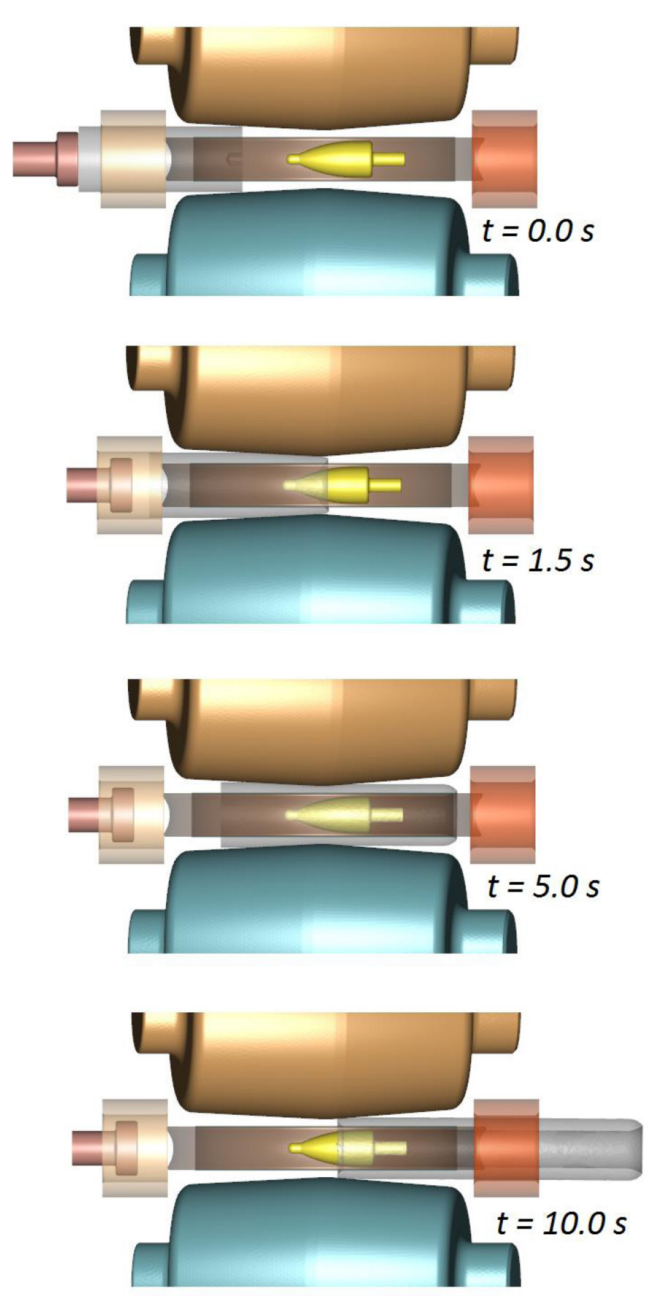

Fig. 4. Progression of the tube piercing process in two-roll Diescher mill 

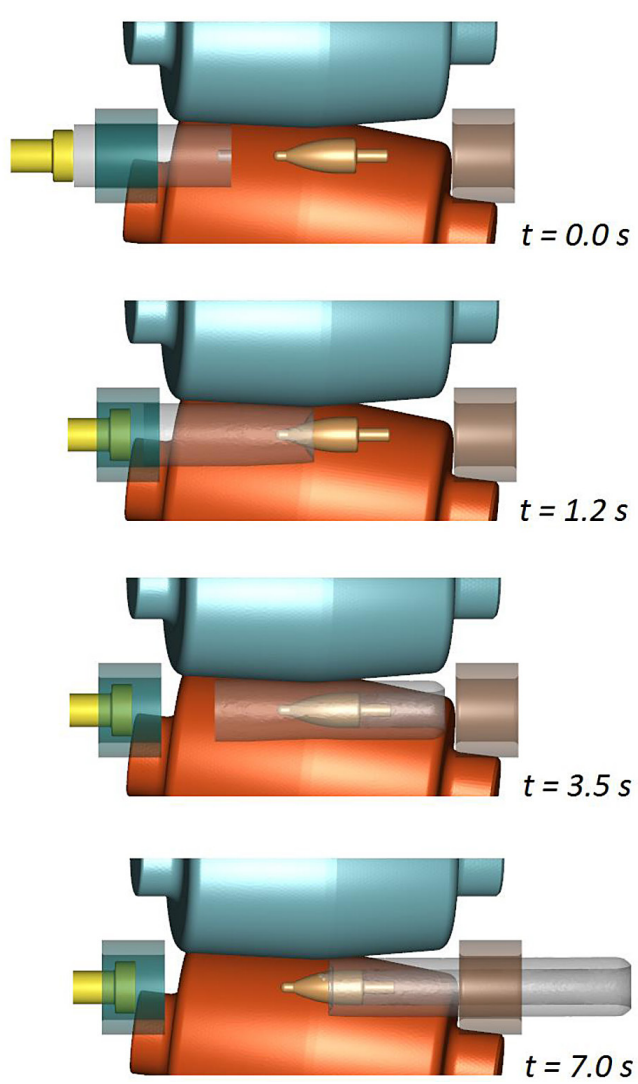

Fig. 5. Progression of the tube shape in the process of three-roll piercing (roll 2 is hidden)

software, based on the finite elements method. The results of the calculations allowed for stating that in both cases a thick-walled tube is obtained. The numerical prognoses of the rolling processes, presented in Figure 4 (two-roll piercing) and Figure 5 (three-roll piercing) show no aspects which

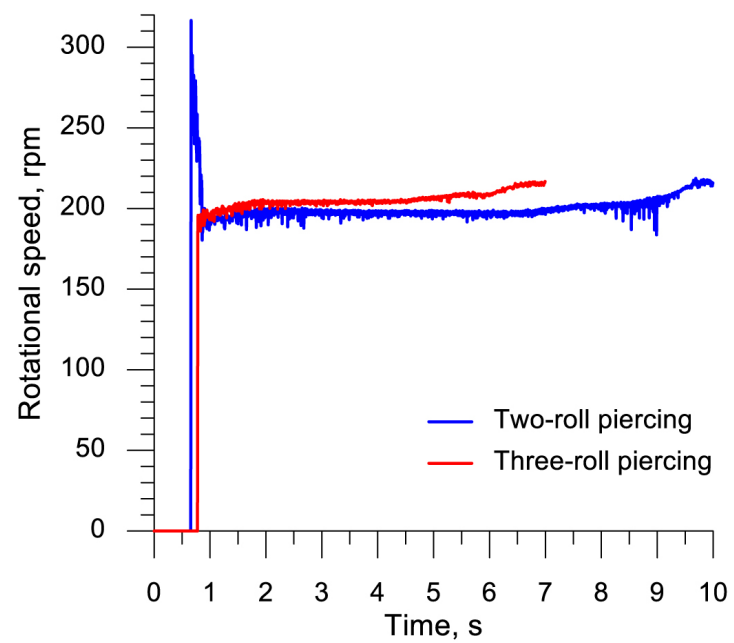

Fig. 6. Distribution of the angular speed of the piercing plug in the piercing process would disrupt the stability of the rolling process. It is to be stated that the rolling process conducted in a three-roll mill is c.a. $30 \%$ quicker. This phenomenon is caused by a more significant total axial force causing the rolled object to move during the process. Using three rolls causes a less significant ovalization of the cross-section, which causes the rotational resistance of the rolled object to decrease. This approach is supported by the chart of the rotational speed of the piercing plug, shown in Figure 6 (upon a minor simplification it can be assumed that the rotational speed of the piercing plug is equal to the rotational speed of the rolled object).

In Figure 7 the tubes obtained in both piercing processes are compared. The dimensions of both tubes are similar, mainly: outer diameter: $56.2 \mathrm{~mm}$ and $56.6 \mathrm{~mm}$, wall thickness: $11.5 \mathrm{~mm}$ and 11.1 $\mathrm{mm}$, tube length: $288.2 \mathrm{~mm}$ and $278.2 \mathrm{~mm}$ (in each case, respectively, the dimensions of the tube obtained by two-roll method first, then by threeroll method). According to the authors, rolling in a three-roll mill, where a thinner-walled tube is obtained, should be deemed insignificantly more effective, since such a tube should allow for reducing energy consumption of the following forming processes, mainly the elongation of the tube.

An analysis of strain in the advanced stage of the tube-rolling process, shown in Figures 8 and 9, presents one with important information. It is to be observed that as far as rolling in a two-roll mill is concerned, the strain values are more significant, especially in the surface layers of the manufactured tube. This phenomenon can be linked to the longer duration of the rolling process, which results in a more significant number of rotations of the rolled product during it forming, causing an increased circumferential flow of the material. The aforementioned flow will lead to an increase in both effective strain and energy consumption of the process.

\section{Two-roll piercing}

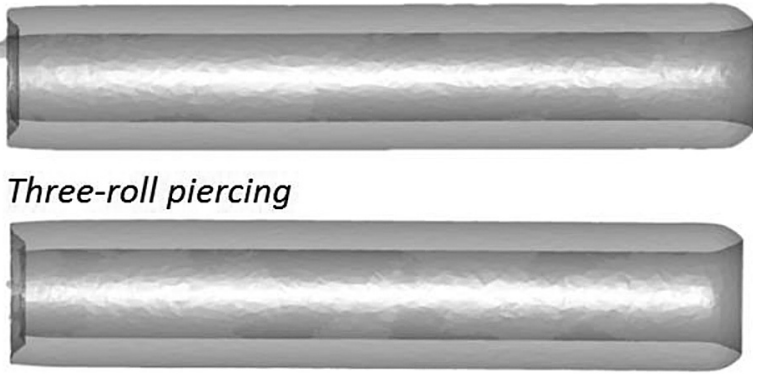

Fig. 7. Tubes obtained in the analysed cases 


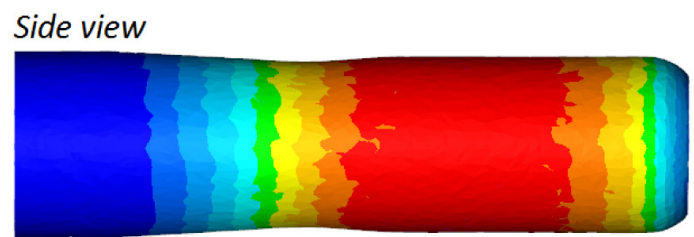

\section{Axial section}

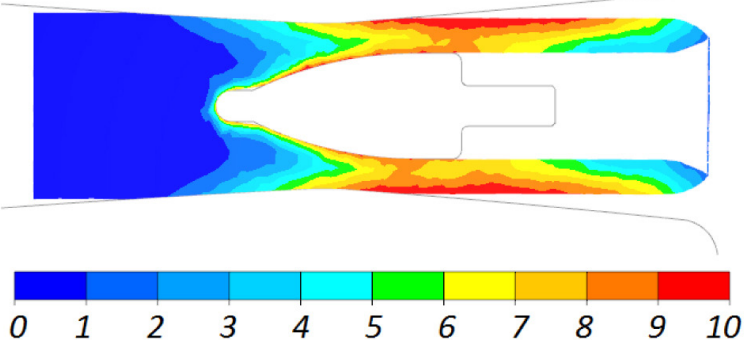

Fig. 8. Distribution of effective strain in the object subjected to the two-roll piercing process; advance of the process: $5 \mathrm{~s}$

The analysis of temperature distribution in the rolled object, shown in Figures 10 and 11 also provides one with important information. In the process of three-roll piercing a tube with a higher temperature of the wall is attained, which is positive and indubitably connected to the shorter forming time, as stated above.

During the piercing process material cracking inside the formed object is to be avoided, since it would result in a lowered quality of the end product. The likelihood of material cracking can be determined based on the damage function, presented in Figures 12 and 13 for the ana-

\section{Side view}

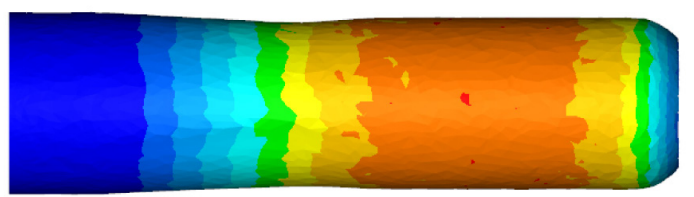

Axial section
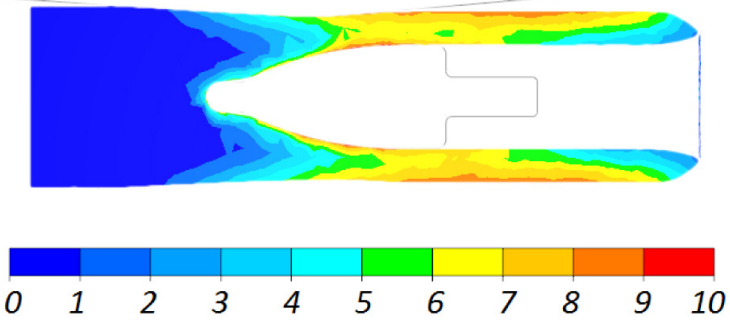

Fig. 9. Distribution of effective strain in the object subjected to three-roll piercing process; advance of the process: $3.5 \mathrm{~s}$

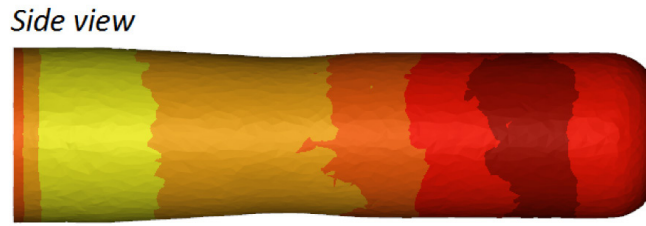

\section{Axial section}

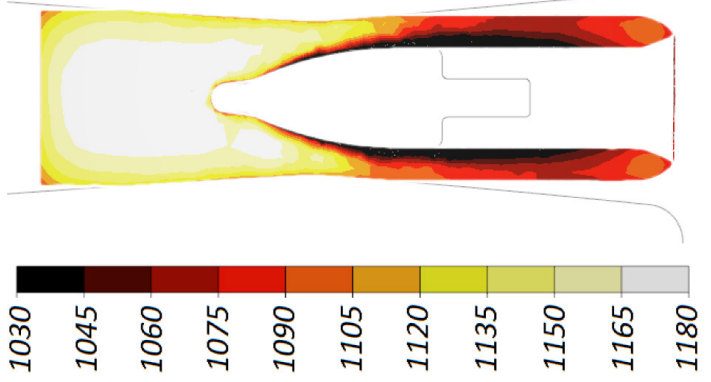

Fig. 10. Distribution of temperature $\left({ }^{\circ} \mathrm{C}\right)$ in the object subjected to two-roll piercing process; advance of the process: $5 \mathrm{~s}$

lysed cases. The data presented in those figures unanimously shows that higher likelihood of material racking occurs in the case of two-roll piercing, which is a result of higher values of tensile stress, which occur in the axial area of the formed product.

Applying FEM allowed for comparing the force parameters in the analysed piercing processes. Distribution of spreading (radial) force on the rolls is shown in Figure 14. It was stated that those forces are insignificantly higher (c.a. 5\%) in the piercing process conducted in a three-roll mill, which is presumably linked to

\section{Side view}

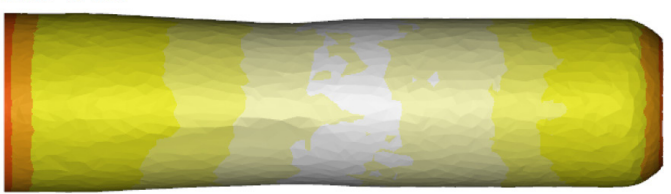

Axial section

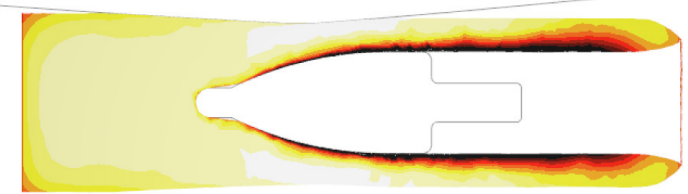

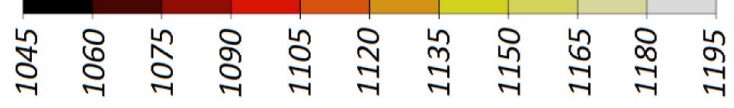

Fig. 11. Distribution of temperature $\left({ }^{\circ} \mathrm{C}\right)$ in the object subjected to three-roll piercing; advance of the process: $3.5 \mathrm{~s}$ 


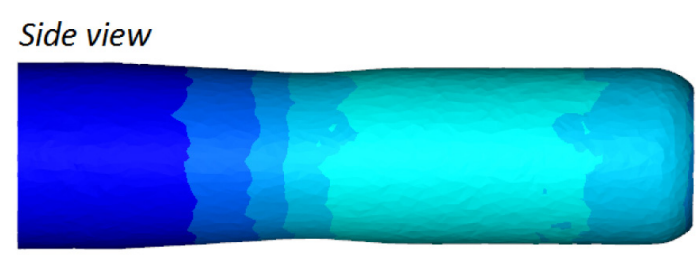

\section{Axial section}
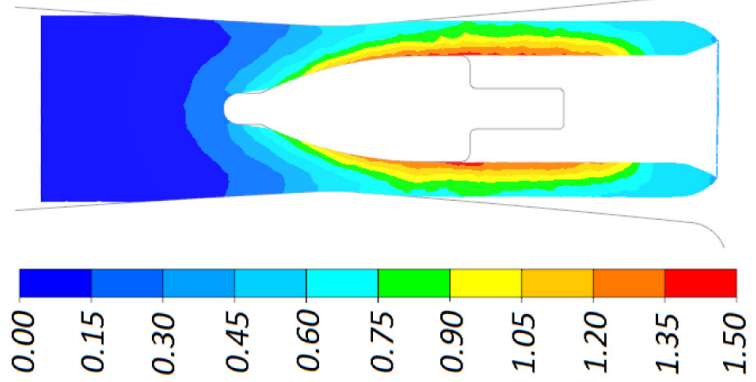

Fig. 12. Distribution of the damage criterion (according to Cockroft-Latham) in the object subjected to the two-roll piercing process; advance of the process: $5 \mathrm{~s}$

the process being more intensive. The distribution of the torque estimated for a single roll was presented in Figure 15. As far as this parameter is concerned it was observed that using three tools leads not only to a decrease of maximum torque (c.a. 18\%), but also in energy consumption during the process. Such conclusion can be drawn based on the average value of the torque, equal $1517 \mathrm{Nm}$ for three-roll method and 2019 $\mathrm{Nm}$ for the two-roll method. Based on this data average power for each roll can be calculated and, further on, after considering the number of rolls and forming time, the energy needed

Side view

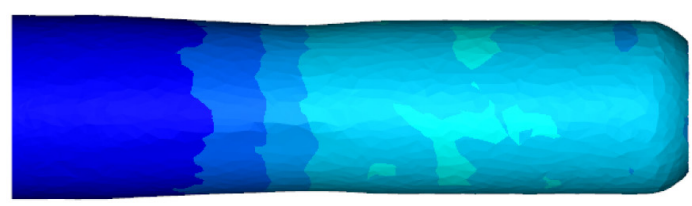

Axial section

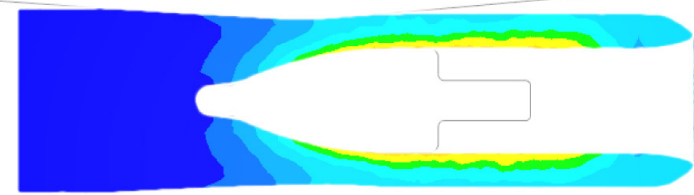

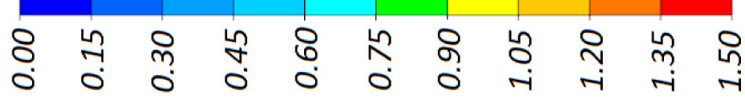

Fig. 13. Distribution of the damage criterion (according to Cokroft-Latham) in the object subjected to three-roll piercing; advance of the process: $3.5 \mathrm{~s}$

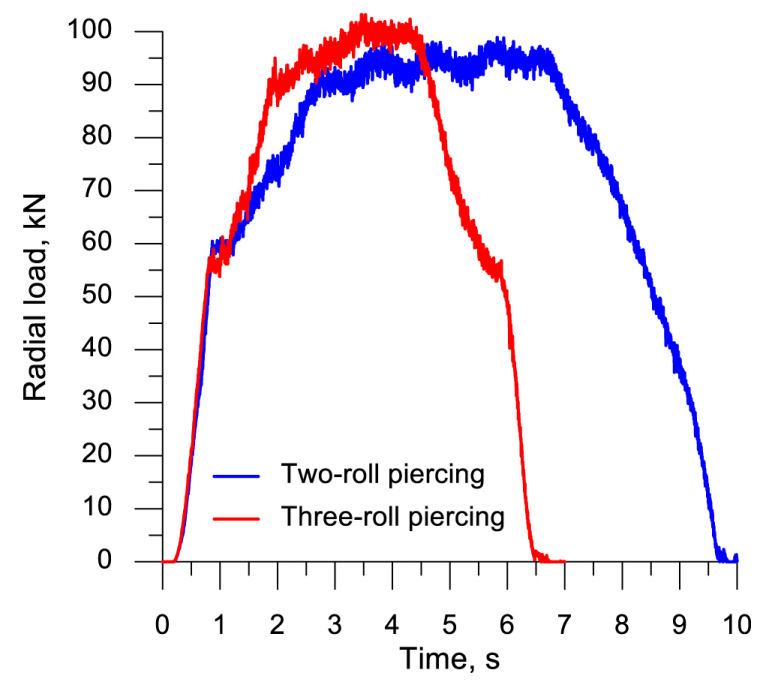

Fig. 14. Distribution of the spreading (radial) force on the roll during the piercing process

for manufacturing a single tube. This energy is equal $185,8 \mathrm{~kJ}$ in the case of the three-roll piercing process and $244.7 \mathrm{~kJ}$ in the case of the two-roll piercing. Therefore, omitting the energy needed for the guiding devices, it can be stated that the three-roll method requires $24 \%$ less energy than the two-roll process.

Since the piercing process conducted in a three-roll mill is more intensive, the axial force on the piercing plug (Fig. 16) is more significant. This increase is estimated to be c.a. $11 \%$. This does not, however, mean a shorter service life of the piercing plug, since the process duration is significantly shorter (c.a. 30\%) than the process of two-roll piercing.

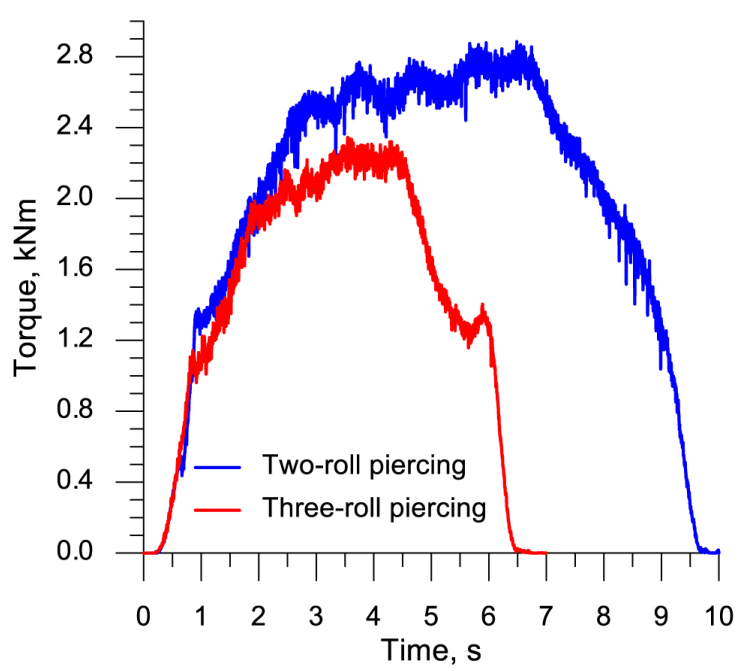

Fig. 15. Distribution of torque on the roll during the piercing process 


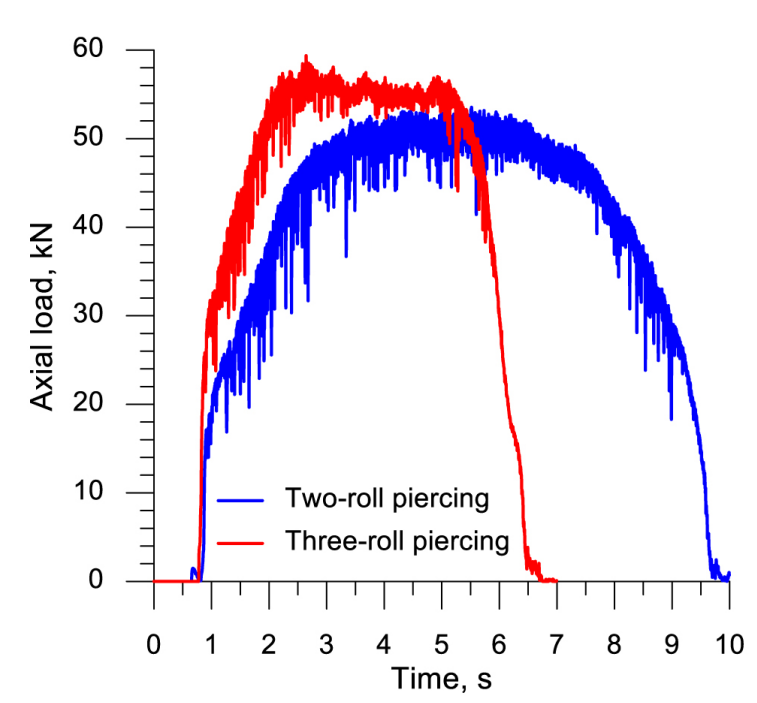

Fig. 16. Distribution of axial load on the piercing plug during the piercing process

\section{CONCLUSIONS}

Based on the comparative analysis of the twoand three-roll piercing processes the following conclusions were formulated:

- three-roll skew rolling process is c.a. $30 \%$ shorter than two-roll skew rolling;

- during three-roll piercing a less significant ovalization of the cross-section occurs, which results in higher angular speed of the manufactured object;

- the tube manufactured in the three-roll mill is slightly thinner-walled and has a higher temperature, which decreases energy consumption of the following forming processes;

- in three-roll piercing method the forming tools (rolls and piercing plug) are subjected to more significant forces than in the two-roll method;

- skew rolling in a three-roll mill is less energy-consuming (c.a. 24\%) than two-roll skew rolling.

\section{Acknowledgements}

The research has been conducted under the project No. 2017/25/B/ST8/00294 financed by the National Science Centre, Poland.

\section{REFERENCES}

1. Urbański S., Kazanecki J., Simulation of piercing process in Diescher rolling mills by the finite element method, Archives of Metallurgy, vol. 40, 1993, no. 4, pp. 419-435.

2. Malinowski Z., Kazanecki J., Urbański S., Thermal-mechanical model of the tube elongation process in Diescher's mill, Journal of Materials Processing Technology, 60 (1996), 513-516.

3. Mori K., Yoshimura H., Osakada K., Simplified three-dimensional simulation of rotary piercing of seamless pipe by rigid-plastic finite-element method, Journal of Materials Processing Technology, 80-81 (1998), 700-706.

4. Yoshimura H., Mihara Y., Mori K., Simplified 3-D FE simulation of rotary piercing controlling rotation of plug. At: Simulation of Materials Processing: Theory, Methods and Applications, Mori (ed.), 2001 Swets \& Zeitlinger, Lisse, 577-582.

5. Ceretti E., Giardini C., Attanasio A., Analysis of Rotary Tube Piercing Process: Simulation and Experimental Results. Proc. of AITEM 01, Sept. 2001, Bari, Italy.

6. Capoferri G., Ceretti E., Giardini C., Attanasio A., Brisotto F., FEM Analysis of Rotary Tube Piercing Process. Tube \& Pipe Technology, 2002, 55-58.

7. Shengzhi L., Dahong C., Zhongjian S., Influence of Cross Angle on Stress and Strain of Tube Blanks During Rotary Rolling. Iron and Steel 36 (2001), 34-38 (in Chinese).

8. Pietsch J., Thieven P., FEM simulation of the rotary tube piercing process. MPT International (2003) 2, 52-60.

9. Ceretti E., Giardini C., Attanasio A., Brisotto F., Capoferri G., Rotary Tube Piercing Study by FEM Analysis: 3D Simulations and Experimental Results. Tube and Pipe Technology (2004) March/ April, 155-159.

10. Komori K., Simulation of Mannesmann piercing process by the three-dimensional rigid-plastic finite-element method. International Journal of Mechanical Sciences 47 (2005), 1838-1853.

11. Barazategiu D. A., Cavaliere M. A., Montelatici L., Dvorkin E. N., On the modelling of complex 3D bulk metal forming processes via the pseudo-concentrations technique. Application to the simulation of the Mannesmann Piercing process. International Journal for Numerical Methods in Engineering 65 (2006), 1113-1144.

12. Pater Z., Kazanecki J., Bartnicki J., Three dimensional thermo-mechanical simulation of the tube forming process in Diescher's mill. Journal of Materials Processing Technology 177 (2006), 167-170.

13. Pater Z., Kazanecki J., Thermo-Mechanical Analysis of Piercing Plug Loads in the Skew Rolling Process of Thick-Walled Tube Shell. Metallurgy and Foundry Engineering 32 (2006) 1, 31-40. 
14. Pater Z., Bartnicki J., Kazanecki J., 3D Finite Elements Method (FEM) Analysis of Basic Process Parameters in Rotary Piercing Mill. Metalurgija 51 (2012) 4, 501-504.

15. Pater Z., Kazanecki J., Complex Numerical Analysis of the Tube Forming Process Using Diescher Mill. Archives of Metallurgy and Materials 58 (2013) 3, 717-724.

16. Zhao Y., Mao J., Effects of feed angle on Mannesmann Piercing in Drill Steel Production. Advanced Materials Research 915-916 (2014), 996-999.

17. Zhao Y. Q., Mao J. H., Liu F. F., Ma Z. H., Experiments and Simulation on Mannesmann Piercing Process in the Drill Steel Manufacture. Strength of Materials 47 (2015) 1, 29-40.

18. Murillo-Marrodan A., Garcia E., Cortes F., Friction Modelling of a Hot Rolling Process by means of the Finite Element Method. Proc. of the World Congress on Engineering 2017, July 5-7, 2017, London, U.K., vol. II.

19. Chastel Y., Diop A., Fanini S., Bouchard P.O., Mocellin K., Finite Element Modeling of Tube Pierc- ing and Creation of a Crack. International Journal of Material Forming (2008) Suppl 1, 355-358.

20. Ghiotti A., Fanini S., Bruschi S, Bariani P.F., Modelling of the Mannesmann effect. CIRP Annals Manufacturing Technology 58 (2009), 255-258.

21. Joun M., Lee J., Cho J., Jeong S., Moon H., Quantitive study on Mannesmann effect in roll piercing of hollow shaft. Procedia Engineering 81 (2014), 197-202.

22. Skripalenko M.M., Bozhenov V.E., Romantsev B.A., Skripalenko M.N., Huy T.B., Gladkov Y.A., Mannesmann piercing of ingots by plugs of different shape. Materials Science and Technology (2016), 1-9 DOI 10.1080/02670836.2016.1145840.

23. Romantsev B.A., Skripalenko M.M., Huy T.B., Skripalenko M.N., Gladkov Y.A, Gartvig A.A., Computer simulation of piercing in a four-high screw rolling mill. Metallurgist 61 (2018) 9-10, 729-735.

24. Stefanik A., Szota P., Mróz S., Dyja H. Analysis of the Aluminum Bars in Three-high Skew Rolling Mill Rolling Process. Solid State Phenomena 220221 (2015), 892-897. 